\title{
Gênero e resistências em filmes de animação
}

\author{
Constantina Xavier Filha*
}

DOI: 10.1590/0103-7307201607902

\section{Resumo}

O presente texto tem por objetivo discutir e problematizar as concepções de gênero da princesa Barbie em um filme de animação e nas falas de crianças, bem como refletir sobre novas possibilidades de feminilidades a partir de uma protagonista de filmes de animação, produzida em experiências de produção de filme com crianças. Os questionamentos a serem debatidos são fruto de pesquisa, com apoio do CNPq, além de projetos de extensão sobre produção de filmes de animação com crianças. A reflexão empreendida entende os filmes como artefatos culturais, e as crianças como sujeitos de direito e com condições argumentativas para discutir e mudar as concepções culturalmente construídas. As figuras das princesas ainda aparecem representadas em determinado padrão de normalização. No processo da pesquisa, entretanto, essas concepções são questionadas e novas produções são realizadas, nas quais novas formas de ser feminino divergem da norma, como formas de resistência aos modelos idealizados.

Palavras-chave: gênero, poder, resistência, filme de animação
* Coordenadora do Grupo de Estudos e Pesquisas em Sexualidades, Educação e Gênero (GEPSEX), Professora do Centro de Ciências Humanas e Sociais, Unidade de Educação, Universidade Federal do Mato Grosso do Sul - UFMS, Campo Grande, MS, Brasil.tinaxav@terra. com.br 


\title{
Gender and resistance in animation films
}

\begin{abstract}
This paper aims to discuss and to problematize the gender conceptions of Princess Barbie present in an animated film and in children talk. It also discusses the new possibilities of femininity from a protagonist of animated films produced by experiences in producing films with children. The issues to be discussed are results of research, with support from CNPq, and extension projects on production of animated films with children. The reflection undertaken understands movies as cultural artifacts and children as subjects with rights and argumentative conditions to discuss and change culturally constructed ideas. The figures of the princesses appear even represented in certain standard standards. In the process of research, however, these concepts are questioned and new productions are performed in which new ways of being female differ from the norm, as forms of resistance to idealized models.
\end{abstract}

Keywords: gender, power, resistance, animation movie 


\section{Jeitos de ser princesa nas falas das crianças: início de conversa}

A figura da princesa parece povoar nosso imaginário e, a cada dia, reaparece nos mais variados artefatos culturais destinados à infância, como filmes de animação, imagens estampadas em materiais escolares, motivos de festas infantis, brindes, brinquedos, entre outros.

As princesas dos contos de fadas receberam, nos dias atuais, novas roupagens e novas tramas em suas histórias, trazendo-as, em sua maioria, para a contemporaneidade, sem lhes mudar as características e o desenrolar da narrativa dos contos clássicos. Novas linguagens também são adotadas. A boneca Barbie ${ }^{1}$, da Mattel, por exemplo, é protagonista, até o momento, de 30 filmes de longa metragem; pelo menos $6^{2}$ deles, nos quais atua como protagonista, trazem em seu título a palavra "princesa".

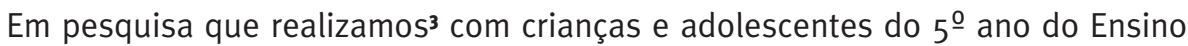
Fundamental de uma escola pública municipal em Campo Grande, capital do Mato Grosso do Sul, nos anos de 2010 e 2011, ao solicitar que desenhassem princesas e sobre elas escrevessem, as narrativas, tanto das meninas quanto dos meninos, apresentaram características físicas semelhantes: branca, loira, magra, alta, cintura fina, cabelo comprido - liso ou levemente cacheado -, sempre de vestido comprido. Entretanto em algumas das produções observadas, houve diferenças destoantes entre as dos meninos e as das meninas. Elas incorporaram em suas narrativas as imagens e as características socialmente aceitas e ensinadas sobre as princesas dos contos de fadas clássicos. Já alguns meninos se detiveram em características diferentes das meninas, descrevendo princesas de cabelo curto, cabelo ruivo, cabelo desarrumado, "princesa dentuça"; princesa de bota, calça comprida e usando vestido na tonalidade azul.

As características pessoais e comportamentais das princesas também foram escritas nas narrativas das crianças. As comuns (de meninos e meni-

1. "De férias na Europa, a cofundadora da Mattel, Ruth Handler, descobriu Lily, uma proeminente estrela dos quadrinhos - uma loira sexy e amoral que enfeitava os painéis dos carros dos homens na Alemanha e Suíça. .... Handler decidiu trazer o modelo de Lily em sua volta aos Estados Unidos e criou uma boneca que podia usar múltiplas 'roupas' - ela a chamaria Barbie em homenagem à sua filha, Barbara”. (Steinberg, 2001, p. 324).

2. Filmes: Barbie, em A Princesa e a Plebeia (2004); Barbie, em as 12 Princesas Bailarinas (2006); Barbie, em a Princesa da llha (2007); Barbie - Escola de Princesas (2011); Barbie - a Princesa e a Pop Star (2012); Barbie, em Super Princesa (2015).

3. No presente texto, utilizo dois tempos verbais, o da primeira pessoa do singular para me posicionar como pesquisadora e também o da primeira pessoa do plural, especialmente quando me reporto às ações coletivas junto com as crianças e os(as) adolescentes na escola; além deles(as), também estiveram comigo nesse processo professores(as) de turmas; acadêmicas do curso de Pedagogia da Universidade Federal, constituindo uma teia de relações coletiva e colaborativa. 
nas) indicavam uma princesa feliz, vaidosa, linda, bonita, simpática, legal, alegre, que adora animais e gostaria de ter um príncipe encantado. Os meninos também afirmaram que as princesas têm amigos(as); são sorridentes e gostam de boneca, vestido e calça. As meninas, por sua vez, falaram em inúmeras outras condutas desejáveis para a princesa, tais como: asseio, doçura, discrição, delicadeza, inteligência, fofura, meiguice, amabilidade. Acrescentaram algumas competências, como gostar de cozinhar, ser prendada, ser divertida, gostar da cor rosa, não ser gulosa e ficar à espera do príncipe encantado.

As características físicas e comportamentais desejáveis das princesas são condizentes, nos textos e nos desenhos das crianças, com o que se espera como ideal da conduta feminina, ensinada social e culturalmente. É interessante observar como essas adjetivações compõem as representações de gênero que marcam a feminilidade ainda idealizada. Tais características estão fortemente presentes nas personagens da Barbie, interpretadas pelas crianças, inclusive na descrição física, em que a imagem da boneca é personificada nas mais variadas princesas em seus filmes.

No presente texto, tenho por objetivo problematizar a figura da princesa como ideal de feminino, bem como pensar em novas formas de feminilidade e masculinidade, a partir de uma experiência específica de produção de um curta-metragem com crianças em projetos de extensão ${ }^{4}$ e pesquisa. Nessa direção, proponho pensar sobre as resistências possíveis nos processos junto com as crianças e, consequentemente, em seus processos de subjetivação.

\section{Entre princesa tradicional e novos jeitos de ser princesa em filmes de animação}

\subsection{Barbie-Escola de Princesas}

No filme Barbie - Escola de Princesas (79 min, 2011), vemos como os filmes podem ser instrumentos férteis do dispositivo pedagógico de educação da infância. Ele descreve o que se espera de uma menina no processo de constituição de sua feminilidade. Para apresentar elementos desse processo, retomarei os principais fatos da história. Neles há aspectos da constituição identitária de meninas, e também de meninos, de forma relacional, a partir da figura da

4. As discussões constantes neste texto são decorrentes de informações coletadas e produzidas no campo empírico de uma pesquisa, com apoio do CNPq, e de dois projetos de extensão da universidade de origem. protagonista. Para esse entendimento, urge primeiramente pensar o conceito de gênero e identidade de gênero. 
Para Louro (1997), a pretensão é entender o gênero como constituinte da identidade dos sujeitos. Para ela, os sujeitos têm identidades “plurais, múltiplas; identidades que se transformam, que não são fixas ou permanentes, que podem, até mesmo, ser contraditórias" (p. 24). A autora, ao afirmar que o gênero institui a identidade do sujeito junto com outros marcadores sociais como a etnia, a classe, entre outros, acrescenta que esse processo transcende o desempenho de papéis, para pensar o gênero como parte do sujeito. Nesse sentido, as identidades de gênero referem-se aos modos pelos quais os sujeitos se identificam, social e historicamente, como masculino ou feminino. Esse processo não é dado, conforme salienta a autora, e, sim, construído.

As identidades são sempre construídas; elas não são dadas ou acabadas num determinado momento. Não é possível fixar um momento - seja esse o nascimento, a adolescência, ou a maturidade - que possa ser tomado como aquele em que a identidade sexual e/ou a identidade de gênero seja "assentada" [ ênfase da autora] ou estabelecida. As identidades estão sempre se constituindo, elas são instáveis e, portanto, passíveis de transformação. (p. 27)

As instâncias sociais - dentre elas, os artefatos culturais, como cinema, livros, entre outros, assim como família, igreja ou escola -, são atravessadas pelos gêneros: “Produzem-se, ou 'engrendram-se'[ênfase da autora], a partir das relações de gênero" (Louro, 1997, p. 25). Essas instituições produzem sujeitos generificados, na medida em que educam para um gênero, produzindo o que Louro chama de "pedagogias da sexualidade e de gênero". Essa pedagogia ocorre de forma "sutil, discreta, contínua, mas quase sempre, eficiente e duradoura" (Louro, 2000, p. 68), em todo espaço social:

Na escola, pela afirmação ou pelo silenciamento, nos espaços reconhecidos e públicos ou nos cantos escondidos e privados, é exercida uma pedagogia da sexualidade. Legitimando determinadas identidades e práticas sexuais, reprimindo e marginalizando outras. Muitas outras instâncias sociais, como a mídia, a igreja, a justiça, etc., também praticam tal pedagogia, seja coincidindo na legitimação e denegação de sujeitos, seja produzindo discursos dissonantes e contraditórios. (Louro, 1999, p. 31)

As identidades são construídas pelos sujeitos em meio às pedagogias da sexualidade e de gênero, permeadas pela cultura. Aprendemos e nos constituímos o tempo 
todo, de forma sutil e contínua, como salienta a autora, porque estamos imersos em discursos que estão a nos dizer sobre o ideal de feminilidade e de masculinidade. Não somos sujeitos passivos nesse processo, segundo Louro (1997); aceitamos, rejeitamos, acatamos - ou não - esses discursos que estão o tempo todo a nos dizer como agir, como ser, de que forma nos conduzir. Nesse processo social e cultural, vamos aprendendo e nos constituindo como masculino ou feminino.

O conceito de gênero, então, parte do entendimento de:

construção social feita sobre diferenças sexuais. Gênero refere-se, portanto, ao modo como as chamadas "diferenças sexuais" [ênfase da autora] são representadas ou valorizadas; refere-se àquilo que se diz ou se pensa sobre tais diferenças, no âmbito de uma dada sociedade, num determinado grupo, em determinado contexto. (Louro, 2000, p. 26)

Esse conceito é relacional e cultural. Não há uma "essência" de ser masculino ou feminino, mas um aprendizado, uma constituição identitária; portanto, podemos constituir formas múltiplas de ser masculino, feminino, ou criar outras formas de ser. Esses aprendizados sociais, no entanto, estão impregnados pela visão binária de ser masculino/feminino, quase sempre indicando uma forma única de ser homem/mulher. Essa norma social determina que o gênero esteja em consonância direta com a heterossexualidade compulsória ${ }^{5}$, ou seja, se nasci com um pênis, serei do gênero masculino e terei uma orientação sexual heterossexual; o mesmo se aplica às mulheres. As pedagogias sociais estão o tempo todo produzindo os su-

5. "Conjunto de valores, normas, dispositivos e mecanismos definidores da heterossexualidade como a única forma legítima e natural de expressão identitária e sexual, que faz com que a homossexualidade, a transgeneridade e as práticas sexuais não reprodutivas sejam vistas como desvio, crime, aberração, doença, perversão, imoralidade, pecado. Como explica Judith Butler, a imposição de heteronormatividade se vincula a processos de produção de corpos, sujeitos e identidades coerentemente sintonizados com a sequência sexo-gênero-sexualidade. Mais do que isso: a heteronormatividade se fundamenta na crença na divisão binária dos corpos (macho e fêmea), e na atração 'natural' entre os 'sexos opostos' (correspondentes, obrigatoriamente, a gêneros distintos, também definidos de maneira binária). Nesse contexto, os gêneros são definidos com base na "matriz heterossexual'[...]." (Carvalho, Andrade, \& Junqueira, 2009, pp. 20-21). jeitos, conjuntamente com outros marcadores: “branquidade”, magreza e juventude. Os filmes são importantes instrumentos desse tipo de educação; por isso, ganham destaque neste texto e em nossos projetos junto com as crianças.

Vejamos como essas questões ganham destaque em um filme protagonizado pela Barbie, que apresenta um jeito de ser princesa e, consequentemente, da forma de viver sua feminilidade, para, posteriormente, pensar novamente sobre as narrativas das crianças e as resistências possíveis nesse processo. 
O filme Barbie-Escola de Princesas ocorre em Gardênia, em uma das instituições responsáveis, no reino, pela educação feminina - a “Escola de Princesas" -, que há mais de cinco séculos ensina as meninas a encontrar seus sonhos e a aprender como ser uma "verdadeira princesa", tendo como lema "Toda garota é uma princesa. Toda garota tem o potencial de ser princesa".

No filme, sorteiam vagas para plebeias ingressarem na escola e, com isso, descobrirem em si o potencial da princesa, atuando posteriormente como dama real. Blair (Barbie), a protagonista do filme, é uma garçonete que trabalha arduamente para ajudar no sustento da família, composta pela mãe e por Emily, sua irmã, pré-adolescente. Emily inscrevera o nome da irmã para concorrer ao sorteio de uma bolsa de estudos da renomada escola. Blair foi sorteada e, a partir daí, a narrativa do filme passa a ser a saga da menina pobre que quer "aprender”/“tornar-se” dama real, já que somente as moças da nobreza receberiam a condecoração de princesa. Independentemente da estirpe da aluna, o currículo da escola visava a promover seu aprendizado e a despertar nela a princesa em potencial, com aulas de etiqueta à mesa, de modos de se vestir, de dança, entre outros conteúdos de aprendizado de uma suposta feminilidade ideal (Xavier Filha \& Bacarin, 2014b).

Na escola, em seu dormitório, Blair conhece duas alunas, que serão suas amigas ao longo da estada na instituição educativa: uma menina de cabelos castanhos, que joga futebol, e uma oriental, que gosta de editar música no computador.

Ao longo do filme, Blair mostra-se desastrada e desengonçada nas aulas de postura e etiqueta; é ridicularizada por algumas princesas que the dizem, de forma arrogante, que plebeias não se ajustam às atividades das sofisticadas aulas. Em cada aula e lição, aprende que o esforço pessoal é capaz de promover mudanças internas nas alunas. Blair assume esse compromisso e se esforça com aulas particulares para atingir o mesmo nível de conhecimento das demais.

Em uma aula de dança real, conhece o príncipe Nícolas, que estuda na Academia de Príncipes, próximo à Escola de Princesas. Dançam juntos e iniciam um sentimento de afeto mútuo.

No decorrer do filme, a protagonista descobre que é filha de família real e resolve reaver o trono a que tinha direito. No final, após lutar contra sua professora, que queria que a própria filha fosse coroada princesa no lugar de Blair, realiza-se o previsto: ela termina a história com o príncipe, com sua família adotiva, e com a célebre frase que coroa a narrativa da história, de que toda "menina é princesa". 
A instituição educativa “Escola de Princesas" cumpre sua função, ao educar meninas com aulas de boas maneiras, etiqueta, postura corporal, dança real e demais estratégias educativas para educar corpos e mentes de alunas. 0 ideal de feminilidade está posto nos vários diálogos, nos ensinamentos cotidianos, que ultrapassam as salas de aula e estão presentes no prédio escolar, no currículo, nas relações cotidianas entre alunas e professoras.

Louro (1999) afirma que o processo de escolarização do corpo contribui para a produção de uma masculinidade ou feminilidade a partir da prática da pedagogia de sexualidade e gênero, como já exposto, além do disciplinamento dos corpos de meninas e meninos.

Os investimentos comumente produzidos pelas mais diversas instâncias sociais, como a escola da Barbie e as escolas da "vida real", também fazem com que haja um investimento contínuo do próprio sujeito nas formas de viver seus desejos, sua sexualidade, seu gênero. No entanto, apesar dos mais variados discursos, o que se pode perceber é que se busca fixar uma identidade como "normal" e ideal a ser seguida. Em nossa sociedade, o gênero está ligado diretamente à orientação sexual, ou seja, “um homem ou uma mulher ‘de verdade' deverão ser, necessariamente, heterossexuais" (Louro, 1999). E isso é evidente no filme.

O filme, apesar de insistir no modelo hegemônico de feminilidade, também apresenta outros jeitos de ser feminino, ainda que de forma periférica. A própria protagonista é desengonçada e desastrada; suas amigas resistem ao único modelo de ser menina: uma gosta de jogar futebol; outra tem habilidades e conhecimentos em informática. É interessante notar os modos de endereçamento do filme, com os quais Ellsworth (2001) nos instiga a pensar. Para a autora, este termo, que é dos Estudos de Cinema, resume-se em “quem este filme pensa que você é?” (p. 11). Isso significa que, ao fazer um filme, a produção, a direção, o roteiro ... todos(as) pensam em um público privilegiado, muito embora nem sempre o consigam atingir. A partir daí, estabelecem formas de diálogo, de significação e identificação com o(a) espectador(a), que "deve entrar em uma relação particular com a história e o sistema de imagem do filme" (p. 14).

Quem o filme Barbie-Escola de Princesas pensa que é o seu público? Como prioriza algumas identidades femininas e com elas estabelece identificação? Como captura meninas e meninos para assistir ao filme, torcer pela mocinha, sonhar com ela? 
A narrativa adotada apresenta a personagem principal como batalhadora, persistente, corajosa e, ao mesmo tempo, sonhadora, doce, loira, romântica, talentosa, além de ser alguém que não resiste ao modelo hegemônico de feminilidade; pelo contrário, insistentemente o persegue. Ao mesmo tempo, mostra outros tipos de feminilidade, ao trazer como coadjuvantes as amigas que questionam alguns dos ensinamentos e condutas desejáveis e cobradas pela escola. O filme tenta capturar vários tipos de feminilidade, mas define-se claramente por um único modelo, o de uma feminilidade dócil e perseverante, que utiliza várias estratégias para se autoeducar e, com isso, conseguir se transformar na "verdadeira” princesa. Sobre esse processo, Tomaz Tadeu da Silva (2003) ressalta:

Fixar uma determinada identidade como a norma é uma das formas privilegiadas de hierarquização das identidades e das diferenças. A normalização é um dos processos mais sutis pelos quais o poder se manifesta no campo da identidade e da diferença. Normalizar significa eleger - arbitrariamente - uma identidade específica como o parâmetro em relação ao qual as outras identidades são avaliadas e hierarquizadas. Normalizar significa atribuir a essa identidade todas as características positivas possíveis, em relação às quais as outras identidades só podem ser avaliadas de forma negativa. A identidade normal é "natural" [ênfase do autor], desejável, única. A força da identidade normal é tal que ela nem sequer é vista como uma [itálico do autor] identidade, mas simplesmente como a identidade. Paradoxalmente, são as outras identidades que são marcadas como tais. ... A força homogeneizadora da identidade normal é diretamente proporcional à sua invisibilidade. (p. 83)

O processo de normalização da princesa Barbie ocorre durante todo o filme. Ela quase nunca põe em xeque essas normas, pois estão tão sacralizadas em sua vida e no modelo de ser feminino, que não lhe resta senão acatá-las de forma resignada. As suas identidades estão dentro do que se convencionou culturalmente ser a norma: ela é branca, heterossexual, tem sangue nobre e vive sob um ideal de feminino. As outras identidades, marcadas como desviantes, incorretas, necessitariam de ajuda, correção, mudança e retorno à ordem e à normalidade.

Essas questões também se encontram nas instituições educativas da "realidade" e nos processos de subjetivação de muitas meninas, mais um elemento estratégico do filme para seduzir e capturar as "meninas reais". Em todo espaço social e cultu- 
ral há pedagogias culturais que, de forma mais explícita, ou mais sutil, apontam as formas desejáveis de ser menina, de ser menino; de bem se portar; de viver masculinidades e feminilidades; de vivenciar expressões de sexualidade; entre tantas outras formas, dentro do que se convencionou ser a normalidade, de exercer identidades e subjetividades.

Outro elemento sobre constituição de identidade de gênero, presente no currículo da escola, são os modos de subjetivação da protagonista. Os modos de subjetivação propostos por Foucault (2004a, 2004b) explicam esse processo contemporâneo de nos tornar sujeitos pensantes e inconclusos, em busca constante por modelos idealizados de feminilidade, pela chamada "perfeição".

As práticas do sujeito para consigo mesmo foram estudadas por Foucault (2004a), que, em entrevista concedida em 1984, ressaltou o objeto de seu estudo, qual seja, o sujeito humano e seus encontros com os jogos de verdade. 0 que é considerado "verdade" pode assumir a forma de ciência ou modelo científico ou de enunciado produzido nas instituições e nas práticas de controle. Para o referido autor, as relações estabelecidas entre o sujeito e os jogos de verdade podem ocorrer por práticas coercitivas, jogos teóricos - ou científicos - e práticas de si. Os indivíduos tornam-se sujeitos com múltiplas identidades em meio a jogos que estabelecem em relação às práticas coercitivas de instituições como a família, a escola, dentre outras; em relação aos jogos teóricos, a partir de discursos que normalizam condutas, os produzem em práticas divisoras; finalmente, por meio do trabalho do próprio sujeito consigo mesmo.

No filme, a Princesa Blair/Barbie faz um trabalho sobre si em meio aos jogos de verdade. Em determinado momento, ela questiona, e quase titubeia, em relação aos seus propósitos de ser princesa. Depois, mediante um intenso processo reflexivo, constitui-se nos preceitos sociais e culturais do que seja o ideal para a feminilidade de uma princesa. Apesar de concordar com eles, ela se firma em algumas resistências, no momento em que sobe uma torre do castelo para se libertar do cativeiro ou quando trabalha para sustentar a si e à própria família no início do filme, ou ainda quando se questiona se realmente poderia continuar na escola. Tais produções de subjetividades, como se observa, ocorrem em processos de negociação, como o que ocorreu com a princesa Barbie nos momentos em que se questionava diante das imposições sociais, mais um dos subterfúgios a que recorre o filme, e dos processos de subjetivação na sociedade atual.

O filme em análise oferece representações de feminilidade a partir da personagem da princesa. Faz pensar sobre os modos de subjetivação da protagonista. Que outras 
formas haveria de forjar nossas imaginações, além das representações hegemônicas de ser princesa desse filme? Como resistir às imposições de um modelo único? Como as crianças podem criar novas formas de ser para elas mesmas? Como elas podem pensar sobre a produção audiovisual produzida para elas, que tenta capturá-las como espectadoras, produzindo novas histórias? Essas questões, entre outras, foram discutidas e problematizadas com grupos de crianças desde o ano de 2010 em nossos projetos de pesquisa e de extensão, que passo a descrever em seguida.

\subsection{A Princesa Pantaneira}

No início deste texto, discorri sobre as narrativas das crianças sobre o que seria ser princesa, suas concepções, características, jeitos de ser. Mesmo sem aparecer nas respostas, temos conjuntamente, por comparação, a imagem do príncipe que forma o par binário dessas representações, ou seja, se a princesa é dócil e frágil, a figura do príncipe é de alguém valente e destemido. Já dizia que as suas falas estavam impregnadas da concepção idealizada do feminino, do modelo Barbie de ser, inclusive muitas delas descreviam as personagens protagonizadas pela boneca para caracterizar as princesas. Eis alguns textos das crianças:

A princesa Rapunzel: Num castelo onde vivia uma princesa chamada Rapunzel, ela sentia um amor pelo príncipe Artur. Uma certa vez o príncipe foi ao castelo e ele gritou: - Rapunzel! E ela desceu o cabelo para ele subir e depois eles fugiram no cavalo branco e foram felizes para sempre. (João, 12 anos, $5^{\circ} \mathrm{B}$ ).

A Cinderela é uma Princesa branca dos cabelos louros que adora ratinho e cachorro. Ela gosta muito de fazer balas e bombons, ainda mais para o Príncipe. 0 sonho de Cinderela era se casar, e seu sonho se realizou, pois ela vai se casar no dia 20/11/2010. (Evelin, 10 anos, $\left.5^{\circ} \mathrm{A}\right)$.

Barbie é uma Princesa branca que gosta muito de sua mãe e de seu irmão. Ela vai se casar com Webbert, um príncipe que está muito feliz com o casamento. (Carla, 10 anos, $\left.5^{\circ} . A\right)$.

Barbie da Ilha era uma menina que morava em uma ilha e conheceu um Príncipe. Ela descobriu que uma pessoa próxima do príncipe era sua mãe. (Marta, 10 anos, $5^{\circ}$. A).

A Rapunzel é bonita e feliz. Ela tem cabelos compridos, é morena e inteligente. Ela gosta da cor rosa. (Mirtes, 11 anos, $5^{\circ}$. A). 
0 nome dessa Princesa é Bela Adormecida. Ela é loira, bonita, magra, feliz e tem seu príncipe encantado, que é lindo. Ela tem uma vida muito boa com seu pai, o Rei, e sua mãe, a Rainha. (Nívia, 10 anos, $5^{\circ}$. A).

Percebemos, nesses textos, a marca da "branquidade" da princesa e do ideal do feminino. Duas das crianças descreveram a princesa protagonizada pela boneca Barbie. Isso se repetiu nas discussões coletivas com o grupo sobre as características físicas e comportamentais da princesa.

Steinberg (2001) estuda a Barbie e observa que ela é uma "verdadeira americana” (p. 328), que sustenta os valores da família. É "heterossexual, auto-suficiente, filantrópica e moralista. Ela também está pronta para conduzir 'outra' pessoa na sua vida, não importa de que cor ou etnia” (p. 328). Aliado a isso, ela é, para a autora, sexualmente virgem; atemporal e exclusivamente temática (p. 328). É altruísta, que renuncia a alguma coisa para o bem dos outros. Esse é um aspecto importante de se ressaltar, dentre muitos, da pedagogia da sexualidade e de gênero desse artefato cultural. A boneca, a partir de seus infindáveis produtos comercializáveis, ensina as meninas "que é mais importante renunciar a um objetivo do que desapontar a quem quer que seja. ... É uma condição feminina se sacrificar para o bem dos outros” (p. 336). Esse também é um dos ideais de várias princesas dos contos clássicos de fadas, e muito bem representado pela personagem Barbie em seus filmes. A autora diz que, na atualidade, se produz um efeito do "currículo da Barbie":

Ela louva a brancura - brancura loura em particular - como um padrão para a beleza feminina; ela torna as figuras anoréxicas, com seios grandes, objeto do desejo masculino. Ela apóia o consumismo desenfreado como uma razão de ser. Ela nunca questiona as virtudes americanas e apóia a supressão do genocídio colonial do passado da América. Sem dúvida, ela é uma cristã, não uma judia, dominante e não contratual. Ela não é uma garota pobre, a Barbie, como repetidamente atestam suas credenciais da alta classe média. Novamente, o currículo pode não ter efeitos - nenhum efeito é garantido -, mas nós temos de tomar cuidado com o terreno no qual a Barbie opera. (Steinberg, 2001, p. 338).

O cuidado a ser tomado, conforme nos alerta Steinberg (2001), com o terreno no qual a Barbie opera, também deve se estender a outros artefatos culturais produzi- 
dos para o público da infância, dentre eles os filmes a respeito dos quais venho tratando neste texto. Não se trata de proibir a existência da boneca e de seus produtos, mas questionar sobre eles com as crianças. Essa seria uma importante função das escolas e dos centros de Educação Infantil: questionar; problematizar; pensar diferente; trazer outros filmes ${ }^{6}$ e artefatos culturais que promovam outras formas de ser mulher e ser homem, ser gente de múltiplas formas de ser, para além do binarismo homem/mulher.

Nessa direção, realizamos projetos de extensão e de pesquisa em uma escola pública com crianças do $5^{\circ}$ ano do Ensino Fundamental, com idades médias de 9 a 12 anos, nos anos de 2010 e $2011^{7}$.

As atividades dos projetos de pesquisa e de extensão, empreendidos com as crianças, tiveram como marcos teóricos os estudos culturais, os estudos de gênero e os pressupostos foucaultianos. Iniciamos com as narrativas sobre as princesas e os príncipes que as crianças já conheciam, para depois propor novas formas de ser feminino e masculino. Essas discussões tiveram como propósito a produção de um filme de animação e ideias para a escrita de um livro infantil. No ano de 2010, as crianças discutiram sobre o ideal de princesa e depois iniciaram a tratar das ideias para a produção de outro tipo de princesa: a que vivia no Pantanal sul-mato-grossense. No ano seguinte, 2011, retomamos a partir desse ponto, com a discussão sobre as produções do ano anterior, com nova turma, para dar continuidade à história e à produção coletiva do roteiro do filme de animação.

Desconstruir com as crianças a ideia idealizada e romântica da princesa foi um árduo processo. As novas possibilidades de ser masculino e feminino eram severamente descartadas pelo grupo de crianças e retornávamos à reafirmação das representações idealizadas de gênero. Iniciávamos, mais uma vez, os debates para entender por que pensavam daquela maneira, perguntando-nos se não poderíamos romper com aquelas ideias e propor outras formas de pensar. Essas questões apareciam, por exemplo, na concepção da aparência da princesa e de suas características comportamentais. A esmagadora maioria queria que a princesa fosse loira e magra, tal como a Barbie. Questionávamos o porquê dessas concepções. Estimulávamos a se olharem e a ver as belezas de tons da própria pele, outras tonalidades de cor e jeitos de cabelos, as muitas formas de nossos corpos. O mesmo ocorreu em relação à figura do príncipe. Ele não poderia ser

6. Uma sugestão é o filme Valente (2012), que traz Merida como protagonista, que questiona os ensinamentos de gênero da mãe para torná-la uma princesa aos moldes tradicionais e casar-se com um príncipe.

7. Outros projetos análogos ocorreram até 2013. 
frágil? Acima do peso? Usar óculos? No início das discussões, essas características eram impensáveis. Aos poucos, as ideias e as concepções passaram a se tornar mais permeáveis a novas possibilidades e diversidades de corpos e jeitos de ser príncipe e princesa. Essas questões merecem discussões sobre as concepções de gênero presentes nas falas e nos desenhos das crianças, que são as mesmas que, em sua maioria, povoam os vários artefatos culturais, como filmes (os da Barbie, por exemplo!) e livros infantis. No entanto, o estranhamento somente advém de discussões a respeito, de provocação da desconstrução da forma de olhar; de problematizações sobre o porquê de pensarmos assim e não de outro jeito. Esse foi o maior desafio encontrado nas ações da pesquisa, que não tinha a pretensão de instituir uma verdade, mas de provocar várias maneiras de pensar a construção coletiva e negociada da história.

Em sequência às discussões teóricas, seguimos os passos da produção do filme: construção de argumento; escrita do roteiro; elaboração das falas; construção de personagens e contextos na fase da pré-produção. Na etapa da produção com as crianças, foram realizadas as filmagens com a técnica de recorte em stop motion de recorte (fotografia quadro a quadro). Elas participaram efetivamente das filmagens: movimentando as personagens e dando-lhes vida; na gravação das suas vozes; na produção de sons para os efeitos sonoros; na música-tema do filme, e no planejamento da pós-produção.

O filme A Princesa Pantaneira ${ }^{8}$, lançado em 2012, conta a história de Camuela, uma princesa que mora no Pantanal e que recebeu dos bichos, seus amigos, o apelido de "Princesa Pantaneira". Tem o jacaré Godofredo e a capivara Sofia, como bichos de estimação. Um dia, ouviu o grito mais assustador de sua vida. Saiu para a sua principal aventura: salvar o príncipe, preso no mais alto da torre, rodeada por bichos enfeitiçados.

Vários elementos levantados nas falas das crianças no início da pesquisa foram problematizados ao longo do processo da construção da imagem dessa nova princesa. Ela é morena, criança, corajosa, alegre, monta e doma cavalo bravo, salva o príncipe, é decidida, às vezes tem dúvidas, sente medo e pede colo, mas logo volta a sonhar, a imaginar e a viver muitas aventuras. A questão de gênero passou a ser amplamente discutida nesse processo de desconstrução da idealização da princesa pelas crianças. Esse conceito teórico, segundo Meyer (2003), aponta para a noção

8. 0 filme foi selecionado para ser exibido no Festival "Mostra de Cinema Infantil de Florianópolis" (2013). de que, durante toda a vida, mediante instituições e práticas sociais e culturais, nos constituímos 
como homens e mulheres, "num processo que não é linear, progressivo ou harmônico e que também nunca está finalizado ou completo" (p. 16). A partir das atividades da pesquisa, outro elemento teórico de gênero também foi acionado, ou seja, seu aspecto relacional. Quando o discutimos, não estávamos falando do universo predominantemente feminino, mas, sobretudo, da constituição dos sujeitos nas relações sociais. Meninos e meninas puderam, a partir das discussões, realizar problematizações, reflexões, brincadeiras, exercitar formas diferentes de pensar, perceber-se como sujeitos e, nesse processo, constituir-se como meninos e meninas de jeitos diferentes dos que se consideravam hegemônicos ... e com isso produzir novos modos de subjetivação.

Os modos de subjetivação foucaultianos são as práticas de constituição do sujeito (Castro, 2009, p. 408). São atividades sobre si, formas de relação consigo mesmo, “técnicas e procedimentos mediante os quais se elabora essa relação; exercícios pelos quais o sujeito se constitui como objeto de conhecimento; práticas que permitem o sujeito transformar seu próprio ser” (p. 409). A partir das inúmeras atividades nos projetos em que se buscou discutir e problematizar os discursos normalizados, as crianças puderam questionar e se questionar sobre o porquê de muitas normas sociais que estavam o tempo todo a subjetivar. Com isso, novas formas de ser foram gestadas, produzidas, pensadas, reformuladas...

Esse processo de constituição de subjetividades, em meio às atividades propiciadas pelos projetos de produção do filme de animação, ocorreu nas relações de poder. Para Foucault (2012), o poder não é algo que se adquira; o poder se exerce. 0 poder vem de baixo. As relações de poder não se encontram em posição de exterioridade com respeito a outros tipos de relações, mas lhes são imanentes. Apesar disso, afirma o filósofo, “lá onde há poder há resistência” (p. 105). Assegura que há pontos de resistência, e que esses pontos estão presentes em toda a rede de poder, sendo, portanto, móveis e transitórios. Alerta-nos a pensar a resistência no plural; suas formas, para Foucault (2012), são “possíveis, necessárias, improváveis, espontâneas, selvagens, solitárias, planejadas, arrastadas, violentas, irreconciliáveis, prontas ao compromisso, interessadas ou fadadas ao sacrifício" (p. 107).

0 autor é enfático em afirmar que, em meio às relações de poder, há resistências. As resistências, no plural, ocorrem na microcapilaridade da vida, nas possibilidades de fuga, de subterfúgios, de saídas possíveis. As resistências em nossas ações com as crianças ocorreram de múltiplas formas: na análise e na discussão dos artefatos 
culturais existentes no mercado e na cultura para a infância (dentre eles, os filmes de animação, os livros); na possibilidade de proporcionar espaço para debate e problematização; no espaço escolar de temas quase sempre silenciados para serem debatidos com crianças; no diálogo aberto e franco com as crianças, com a confiança de que podemos aprender com elas, desde que possamos propiciar espaços para a escuta sensivel; na possibilidade de produzir linguagem audiovisual e filme de animação, trazendo as crianças como autoras de histórias e partícipes dos demais processos de produção do filme, sabendo que, na maioria das vezes, elas são receptoras desses artefatos, sem reflexão sobre seus modos de produção; na possibilidade de discutir as relações de gênero e pensar em novas possibilidades de ser menino, menina ou quem se quiser ser.

\section{Breves palavras ... para (não) terminar}

Iniciei este artigo tratando de um tipo de feminilidade no filme de animação da grande indústria: Barbie-Escola de Princesas. Nesse artefato cultural, coexistem o ideal de feminilidade, ainda presente na cultura, e novas formas de resistir a essa normatização, com a presença das amigas de Blair/Barbie na trama do filme. Em seguida, apresentei a experiência de produção de filme de animação realizado com crianças em projetos de pesquisa e extensão para a produção do filme de animação $A$ Princesa Pantaneira. Nesse processo, percebem-se as resistências possíveis em meio às relações de poder que tentam nos capturar o tempo todo. Resistências de produzir junto com as crianças ... resistências possíveis de pensar sobre outras formas de feminilidade e masculinidade ... em novas formas de ser...

A experiência de produzir filme de animação com as crianças fez-nos pensar também na possibilidade de resistências diante das imposições adultocêntricas e da necessidade premente de indagar sobre os filmes como artefatos culturais. Comumente, os filmes são utilizados nas instituições educativas para "passar o tempo" ou como instrumento pedagógico, retirando deles conceitos para aprofundamento dos conteúdos curriculares. Os filmes da Barbie, por exemplo, são usados, em especial em alguns centros de Educação Infantil, nos momentos de entretenimento, sem uma discussão sobre o que eles estão a educar, a forjar determinado tipo de feminilidade e a provocar formas de identificação com as crianças. Urge pensar sobre os modos de endereçamento dos filmes; provocar discussões com as crianças sobre as várias formas de educar e aprender mediante os vários artefatos culturais, em especial os 
filmes de animação, tão aceitos e vistos pelas crianças, devido à sua linguagem audiovisual, lúdica, colorida, dinâmica. Provocar questionamentos e problematizações a respeito dos filmes sem pedagogizá-los, promover momentos de entendimento de como se produz a linguagem audiovisual, produzir filmes com as crianças e, com isso, torná-las também sujeitos desse processo, e não somente alguém que recebe as informações sem questionamentos, eis os grandes desafios que empreendemos nos últimos anos com nossas pesquisas e projetos de extensão. Descontruir as figuras da princesa, questionar e produzir outras formas de ser princesa, de ser príncipe, de ser criança, de ser adulto, de ser gente... Eis um delicioso desafio! 


\section{Referências bibliográficas}

Carvalho, M. E. P. de, Andrade, F. C. B. de, \& Junqueira, R. D. (2009). Gênero e diversidade sexual: um glossário. João Pessoa: Editora da UFPB.

Castro, E. (2009). Vocabulário de Foucault. Belo Horizonte: Autêntica.

Ellsworth, E. (2001). Modos de endereçamento: uma coisa de cinema; uma coisa de educação também. In T. T. da Silva, Nunca fomos humanos. Belo Horizonte: Autêntica.

Foucault, M. (2004a). A ética do cuidado de si como prática de liberdade. In M. Foucault, Ditos \& escritos V. Ética, sexualidade, política. Rio de Janeiro: Forense Universitária.

Foucault, M. (2004b). O retorno da moral. In M. Foucault, Ditos e escritos V. Ética, sexualidade, política. Rio de Janeiro: Forense Universitária.

Foucault, M. (2012). História da sexualidade 1. A vontade de saber (22a imp.). Rio de Janeiro: Graal.

Louro, G. L. (1997). Gênero, sexualidade e educação. Uma perspectiva pós-estruturalista. Petrópolis, RJ: Vozes.

Louro, G. L. (1999). Pedagogias da sexualidade. In G. L. Louro (Org.), O corpo educado: pedagogias da sexualidade. Belo Horizonte: Autêntica.

Louro, G. L. (2000). Currículo, género e sexualidade. Porto: Porto Editora.

Meyer, D. E. (2003). Gênero e educação: teoria e política. In: G. L. Louro, J. Neckel, \& S. Goellner (Orgs.), Corpo, gênero e sexualidade: um debate contemporâneo. Petrópolis: Vozes.

Silva, T. T. da. (2003). A produção social da identidade e da diferença. In T. T. da Silva, Identidade e diferença: a perspectiva dos estudos culturais. (2a ed.). Petrópolis, RJ: Vozes.

Steinberg, S. R. (2001). A mimada que tem tudo. In S. R. Steinberg, \& J. L. Kincheloe (Orgs.), Cultura infantil. A construção corporativa da infância. Rio de Janeiro: Civilização Brasileira.

Xavier Filha, C., \& Bacarin, T. I. (2014b). O mundo da Barbie em "Escolas de Princesas" e em "As três Mosqueteiras". In C. Xavier Filha (Org.), Sexualidades, gênero e infâncias no cinema. Campo Grande: Editora da UFMS.

Filme Barbie - Escola de Princesas (EUA, 79 min). Roteiro de Elise Allen; Produção de Schawn McCorkindale e Shelley Tabbut; Direção de Zeke Norton

Submetido à avaliação em 13 de junho de 2015; aprovado para publicação em 18 de outubro de 2015. 